\title{
Interpersonal Relationships and Human Biofield
}

\author{
Khaled Zahran S* \\ Personality and Social Psychologist, Egypt
}

ISSN: 2639-0612

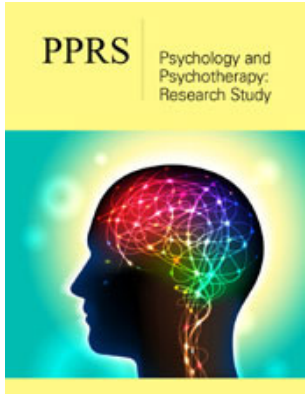

*Corresponding author: Khaled Zahran S, Personality and Social Psychologist, Egypt

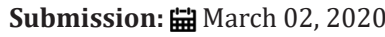

Published: 㘹June 23, 2020

Volume 3 - Issue 5

How to cite this article: Khaled Zahran S. Interpersonal Relationships and Human Biofield. Psychol Psychother Res Stud. 3(5). PPRS. 000573. 2020.

DOI: 10.31031/PPRS.2020.03.000573

Copyright@ Khaled Zahran S, This article is distributed under the terms of the Creative Commons Attribution 4.0 International License, which permits unrestricted use and redistribution provided that the original author and source are credited.

\begin{abstract}
Many factors stand behind interpersonal relationships, most of them experimentally and socially approved to be social and personal factors. Very few writes pointed at or discussed human bio-field or human chemistry as hidden factor(s) that may affect such relationships. This article is a primary trail that introduces such hypothesis through theoretical backgrounds.
\end{abstract}

Keywords: Interpersonal relationships; Human energy field/human biofield; Intimate relationships; Love and hate relationships and body chemistry

\section{Interpersonal Relationships}

Interpersonal relationship is a strong deep or close association between two or more people that may rang in duration from brief to enduring. There are many types of interpersonal relationships, as intimate relationships, as in romantic relationship generally. On the other hand, there are hate and pathological relationships, as abusive, codependent and narcissists. Social connections are essential for health and well-being. People who social needs go unmet have greater incidence of depression, weaker immune systems, and higher mortality rates compared to those with close connections [1]. There are mainly three reasons that drive human to establish relationship; need to belong, as Maslow's hierarchy of needs, such as children's attachment to their parents, second, social exchange, coast-benefit relationship, relation satisfaction based on: rewards, coasts and comparison level.

Finally, sense of self, self that consists of feelings and beliefs based on interactions with others. Interpersonal relationships are dynamic systems that change continuously during their existence; have a beginning, a life span and an end. Human beings are innately social and shaped by their experiences with others. Healthy relationships built on a foundation of secure attachments. Attachment requires sensory and cognitive processing that leads to motor responses. There is neurological basis of attachment, as the development of hormone systems; oxytocin, dopamine, prolactin, etc. and hypothalamic-pituitary-adrenal axis. A review of the research literature on interpersonal communication suggests two very important conclusions:

1. The more people attracted to one another, the more they will communicate with each other; and

2. The more we attracted to other person, the more influence that person has on us in interpersonal communication [2].

Wright in his research about personality and interpersonal attraction, found that: a person who is attractive as a friendship choice is: one who can communicate freely and unguardedly, who is open minded, cooperative and not overly serious-minded, who is a source of rewarding responses, express liking and interest, and is social and outgoing [3]. Friendship and romantic relationships are advantageous at a fundamental level. Friends provide emotional and social support as well as assistance during crisis [1]. One of the most prominent works in emotional relationships is Sternberg theories about love and hate. Love in his theory has three components; intimacy: which encompasses the feelings of closeness, connectedness, and bondedness, passion: which encompasses the drive that leads to romance, physical attraction, and sexual communication, and commitment: which encompasses the decision of love then to maintain this love [4]. 
While, in his theory of hate, he said that hate encompasses of three components: negation of intimacy, passion and commitment. Which means that hate is characterized by repulsion and disgust, intense anger or fear in response to a threat, and some cognitions that reviewing the target as subhuman, the target plans actions contrary to the interests of the in-group, the target is achieving some success in its goals, finally the perception comes reality. He said that we might change such perception by "brain washing" [5]. Some factors affect relationships, especially intimate ones, as personality characteristics, sexual attraction, mutual desire, similar social background and interests, all promote bonding, attachment and bringing lovers together. Psychologists identify three components for "rapport" relationships-which describe harmony and affinity for ongoing relationships, rather than first time interaction-mutual attentiveness; an interest in each other, coordination; balanced interaction, and positivity; caring attitude [1].

Besides, such social and psychological factors, there are chemistry and biology factors. Studies exploring the chemistry of romantic love and the hidden biochemical process that take place in brain when people fall in love showed that love fortified by oxytocin, which fosters bonding and attachment [6]. Helen Fisher, in her research about love, showed that romantic love-which is a cultural universal characterized by, at least, two emotions: attraction and attachment. Human and mammals may share similar brain chemistry for attachment as well. Findings from other studies showed effects of oxytocinergic transmission suggest that the endorphins, oxytocin and vasopressin interact and/or operate in conjoining neuronal systems [7]. Liebowitz hypothesized that the transmission from attraction to romantic love and attachment, grounded in brain physiology. The endorphin system begins to take over, giving partners feelings of safety, stability, and peace. As feelings of attachment, grow the production of oxytocin and/ or the sensitivity of receptor sites for such peptides increase as well [7]. In Campbell K [1] and others 2018 study, interpersonal chemistry themes were: reciprocal candor, which refers to open and meaningful communication. Mutual enjoyment; enjoy in each other company. Attraction; biologically passionate attraction. Similarities; shared hobbies, beliefs, goals, demographic traits. Person ableness; positive interpersonal attribution. Love; deep unconditioned regard for each other. Instant connection; rapport immediately. Indescribable; inability to describe chemistry [1]. Some studies also showed a relationship between human pheromones and sexual attraction. For example, neither males nor females can perceive ovulation in humans consciously, which associate with numbers of physiological and behavioral changes in sexual attraction, but one unconscious mechanism associated with these menstrual cycle changes might be olfactory perceptions. This may use olfactory signals for the transmission of biologically relevant information [8].

Few studies talked about the relationship between attraction among interpersonal relationships and electromagnetic field. In their study, Seifert, F. and Michel, L. talked about the hypotheses physiological and psychological process responsible for long-term love, involve a concept called "energetic compatibility", which refers to electromagnetic field inherent to one's body, such energy mentioned in Eastern philosophy medicine- interacts with the physical environment and energy system of other living organisms. Results showed that romantic attractions are the result of energetic imprint at the DNA level from the opposite gender parent at the moment of birth [9].

In addition, Ramkumar and Priyal study, suggested that auraas electromagnetic field of human body - is strongly associated with interpersonal attraction and communication, and considered as a tool for bridging generation gap by increasing interpersonal effectiveness [10]. Murstein \& Hadjolian [11] found that opposite sex photographers of fingertips aura were bigger as compared to same sex. Concluding from their experiment and their survey to literature, they suggested that fingertips aura is a promising measurement device in the study of interpersonal attraction. In addition, they suggested that further researches might concern itself with the relation of auras and physical attractiveness, similarity, and self-esteem and other variables studied earlier in interpersonal attraction experiments, it will be also valuable to study kinds of relationships; marriage, dating, engagement, divorce with aura pattern.

\section{Human Energy Field/Human biofield}

Since early times, ancient oriental legacy coined "aura" concept, to refer to "human energy body" as scientific concept, eastern practices, both medical and spiritual, are initially directed at correcting the aura, the spiritual body to fix physical body problems. Aura defined as; distinctive atmosphere or quality that seems to surround and generated by person, thing, or place. It is a distinct atmosphere surrounding a given source, a subtle sensory stimulus, as an aroma [12]. Another definition coined by Hogan K [13] who suggested aura as a translucent glow can be seen surrounding a person under certain circumstances. Some writes evaluated aura as thermal energy; such thermal energy radiated from human body, and act as electrostatic field around a person, as electrical ionized fields, also, these electromagnetic radiation waves are up to one hundred kilocycles, which generated by muscle action and possibly radiated at any time, and may exist in a complex mixture around a person's body [14]. Aura is an electro-phonetic vibration response to some external excitation. The human body functions as electro chemical energy system. Human is field of energy, part of everything that pulses and vibrates life. All mental activities involve electrostatic or electromagnetic energy-information exchange, and "aura's energy-information" used to analyze a patient's psychological and emotional states, accurately. Aura electromagnetic radiation differs in its frequencies with its basic six colors: red, orange, yellow, green, blue and purple. Its frequencies are usually in the range of $100-800 \mathrm{MHz}$, and generally exist in a range between and within TV and FM waves and moderate to strong microwaves. Emotional body can be detected 4 to 18 inches away from the physical body, while health level can be detected up to 4 inches away from the physical body [15].

Peters HF [16] work represents the first truly comprehensive systems-level mapping of the structure and mechanisms of the human biofield and their relation to biochemistry and physiology. 
He was the first one who replaced concepts as aura, charka with human biofield. He said that the movement of energy and information in the body field affects emotions and consciousness. He defined human biofield as an intelligent, self-organizing, selfcorrecting, self-maintaining energetic and informational structure that functions at the level of QED (quantum electrodynamics), and quantum holography. Body field and physical body are independent, allowing everything from DNA to cells; real chemical processes drive biogenetic reality, and body field directing information that maintains that biochemistry. Schwartz G [17] and others suggested in their report about measuring electromagnetic fields created by physical movements of human body, that human body function as a strong antenna and/or receiver for electrostatic body motions, which may serve as a new method for investigating interpersonal dynamic energy system interactions in psychology, medicine and healing.

Their report was first link between psychical phenomena and human body energy. Green and colleagues measuring "anomalous electrostatic phenomena in exceptional subjects" inspired them. They suggested many factors that may influence magnitude of electrostatic charge, including sex, family history, personality, climate, clothing, energy source in the vicinity and the nature of social relationships. For example, love, intimate or bonded relationships may be associated with greater electrostatic body-motion effects, greater antenna-receiver effects, and there for greater dynamical energy systems interaction effects [17]. Living systems are complex, nonlinear, dynamic, self-organizing systems at a global or holistic level according to principles of nonequilibrium thermodynamics of open systems and chaos theory. Rubik, in his research about human bio-field as a pilot study, extended the bio-information concept from what stored in biomolecules to that transmitted by energetic signals, such as Biophotons. Life is in constant communication each moment, exchanging energy-imbued-information within and between its multiple levels of organization in order to maintain its integrity [18]. The fundamentals of a theory of the human biofield; the biofield hypothesis provides a scientific explanation of how holistic interventions (engaging mind-body-spirit) may work by impacting directly the global regulatory processes of life rather than particular physical structures of the body.

The key points of biofield hypothesis are:

a. There is a complex, endogenous, multi-dimensional field of the human being that consists of electromagnetic and subtler fields within and around the body.

b. This complex field conveys vital information in both directions and is central to the integration of the human being [18].

Some writes referred to human biofield (aura) as an existence that transmutation into relationships, in like, hook or averse, in light of their vibrations which match or repel each other. Smith J [19] referred to aura as human fingertips, that everyone has a unique within itself. Through intimate relationships, aura color changes their colors from yellow, orange, and red, for example. Smith WL
[20] suggested in his article about human electromagnetic energy field that human interpersonal communication has an inherent connection, that human body could act as an aerial that has the potential for simultaneous transmission and reception of energy with its environment. Human consciousness is now a theoretically quantifiable phenomenon and at least partly measurable as an electromagnetic energy field radiating out from the human body. Jack Sarfatti applied superstring theory of physics on human biofield nature and component. Very small vibrating stings combine with other strings of similar resonance; smaller 100 billion times than a proton, then combination and re-combination of resonant strings form the particles of matter, which we are familiar. The oneness of mind body and how it may bundle as vibrating energy is interconnected to everything else in the universe, which may call "cosmic connection".

Vibrating bundle of energy; vibrating strings of mutual harmonic resonance that form electromagnetic field operating at a given frequency, not as frequency of radio station, create field that influence around their physical selves. For example, embarrassment is an emotion, the expression of an emotion is a though, thoughts are energy, there for there is a fundamental connection between the intrapsychic and intrapsychic communication aspects and postquantum mechanical, physiological and psychological aspects of consciousness. Hence, there is a connection between super string theory, post-quantum physics, and human anatomy, physiology, psychology and the communication discipline when discussing the subject of interpersonal communication [21,22].

\section{Suggested Hypothesis}

Human biofield affects interpersonal communication.

\section{Conclusion}

Many studies showed the relationship between interpersonal communication and personal/social factors that affects it. Few ones pointed at the suggested effect of human biofield and interpersonal relationships. This article emphasis the previous idea and suggests for more laboratory studies to identify in which way this effect may happen. Interpersonal relationships/communication is one of the most challenges from the down of history until recent times, affect human, as well as society's well fare. This article demonstrates more on human biofield as a new approach for manipulating such obstacle that may handle the problem in the light of psychical, postquantum and physiological aspects, as well as previous handled social and psychological ones.

\section{References}

1. Campbell K, Nelson J, Parker ML, Johnston S (2018) Interpersonal chemistry in friendships and romantic relationships. An International Journal on Personal Relationships 12(1): 34-50.

2. McCroskey JC, McCain TA (1974) The measurement of interpersonal attraction. Special Reports. Speech Monographs 41: 261-266.

3. Wright PH (1965) Personality and interpersonal attraction: Basic assumptions. Journal of Individual Psychology 21(2): 127-136.

4. Sternberg RJ (1986) A triangle theory of love. Psychological Review. American Psychological Association 93(2): 119-135. 
5. http://robertsternberg.com/hate/

6. DeMaria R (2019) The chemistry of relationships: Emotions, the brain and the experience of love. National Healthy Marriage Resource Center.

7. Fisher H (1994) The nature of romantic love. Research Commentary. The Journal of NH Research 6: 59-64.

8. Grammer K (2005) Human pheromones and sexual attraction. European Journal of Obstetrics, Gyneocology and Reproductive Biology 118: 135142.

9. Seifert F, Michel L (2019) Exploring the hypothesis of energetic attractions in romantic compatibility. Energetic Compatibility, p. 18.

10. Ramkumar N, Priyal V (2013) Examining the relationship between positive aura, interpersonal effectiveness and generation gap. Journal of Contemporary Research in Management 8(4): 61-74.

11. Murstein BI, Hadjolian SE (1977) Fingertip aura and interpersonal attraction. J Pers Assess 41(3): 225-265.

12. http://www.merriam-webster.com/dictionary/aura

13. Hogan K (2019) Human aura research experiment Craig Lang, CHT.
14. Tart CT (1972) Concerning the scientific study of the human aura. Journal of the Society of Psychical Research 64(751): 1-21.

15. https://www.speakingtree.in/allslides/the-scientific-evidence-ofhuman-aura/119308

16. Peter HF (2008) Decoding the human body field, the new science of information as medicine. Healing Arts Press, Canada.

17. Schwartz G (1996) Report: Electrostatic body-motion registration and the human antenna-receiver effect: A new method for investigating interpersonal dynamical energy system interactions. subtle energies and energy medicine. Subtle Energies 7(2): 149-184.

18. Rubik B (2019) The human biofield and a pilot study on qigong. Philosophy, pp. 151-170.

19. Smith J (2014) How spiritual is the relationship with your partener?

20.Smith W (2019) The Human electromagnetic energy field: Its relationships to interpersonal communication.

21. (2019) Aura and relationships.

22.http://en.wikipedia.org/wiki/interpersonal_relationship. 